This is an author accepted manuscript version of Hannigan B. and Burnard P. (2001) Preparing and writing an undergraduate dissertation. Nurse Education in Practice 1 (4) 175-180 http://dx.doi.org/10.1054/nepr.2001.0028

\title{
PREPARING AND WRITING AN UNDERGRADUATE DISSERTATION
}

\begin{abstract}
$\underline{\text { ABSTRACT }}$
Nurses studying for undergraduate degrees are often required to produce a dissertation. Usually, this will be a piece of work of around 10,000 words in length. In this paper, we discuss the characteristics of a good dissertation, and discuss a range of strategies which students might find useful as they work towards dissertation submission. Particular areas that we concentrate on include: getting started; working with supervisors; defining a clear topic area; planning work and timetabling; locating and critiquing literature; writing up the literature review; linking theory and practice; and knitting the dissertation together.
\end{abstract}




\section{INTRODUCTION}

Many nurses study for undergraduate degrees, either whilst working towards their initial nursing qualifications or at post-registration level. The work that students studying at bachelor's degree level submit varies from higher education institution to higher education institution. Often, however, students are required to produce an undergraduate dissertation. Typically, this will be a piece of work of around 10,000 words in length. At undergraduate level, students working on dissertations are not usually required to undertake any original research; this is often left to those studying at postgraduate level. The skills needed to complete a research dissertation are different from those needed to complete a literature review-based dissertation. In this paper we concentrate specifically on the latter of these two variants.

Seeing a dissertation through from start to finish can seem daunting. Currently, there appears to be relatively little published work in the nursing literature to guide students and supervisors through the dissertation process, although some small-scale research into the role of the supervisor has been produced (Snowball et al 1994). Our aim in this article is to fill this gap, by providing some guidance for those who are embarking on the dissertation process. In doing this, we draw on our own experiences of academic writing, and on our experiences of supervising students.

\section{WHY DISSERTATIONS?}

Invariably, the dissertation is the longest single piece of work that students following undergraduate degrees are required to write. It will also usually be the last, or one of the last, pieces of work that students are asked to submit. Reflecting its length and the effort that goes 
into its production, the dissertation is also likely to attract a large proportion of the overall marks available for the award of the final undergraduate degree.

It is worth noting that there are identifiable criteria for the academic level of work expected from undergraduate students doing bachelors degrees. The Quality Assurance Agency for Higher Education has identified, amongst other quality indicators that apply to work at undergraduate level, that honours degree students should demonstrate:

The ability to manage their own learning, and to make use of scholarly reviews and primary sources (e.g. refereed research articles and/or original materials) appropriate to the discipline. (QAA for HE 2001)

Anyone who wants to be clear about the learning outcomes expected of an undergraduate student is advised to read this short document published by the QAA.

Dissertations are a test of a number of important skills. The completion of a good dissertation is a demonstration of the student's ability to define a topic area, and to maintain a clear focus on this throughout. A dissertation tests the ability of the student to locate and obtain relevant literature, and to demonstrate skills in literature reviewing. A good dissertation also provides evidence of the ability to structure work, and to organise material in a clear and logical way. Finally, and importantly in the context of a practice-based discipline such as nursing, the dissertation is an opportunity to study, in depth, both theory and practice in relation to a particular clinical field. We consider each of these areas in more detail below.

\section{GETTING STARTED}

At the outset, it is important to read and understand exactly what is required of the dissertation. This means reading, closely, the guidelines for the dissertation that are produced 
by the university to which the completed piece of work is to be submitted. Key areas to clarify include: the exact permitted word length of the dissertation, and the penalties which might be incurred if the final piece of work is over (or, more rarely, under) this length; the date that the completed work has to be submitted; and the mechanisms that exist for the negotiation of extensions to this deadline. It is also important to be clear about exactly what it is that the dissertation guidelines specifically ask for. A dissertation might, for example, need to include both a literature review and a research proposal, or a literature review and a proposal for a service development. Other points to be clear about include the university's requirements for the presentation and submission of the final piece of work. Often, universities expect two or more copies of a submitted dissertation. Many universities also expect that dissertations submitted to them be bound in a particular fashion.

There will, undoubtedly, be a range of other issues that will need clarifying, both at the outset and as work on the dissertation progresses. A key person to help in all of these matters is the dissertation supervisor, being the member of academic staff whose job it is to help the student through the dissertation process. Whilst the final submitted work is ultimately 'owned' by the student alone, the supervisor's role in guiding the student through from start to finish is often a critically important one.

At the earliest stage it is important that students and supervisors make contact. An early task may be to clarify mutual expectations around respective roles and obligations. Groundrules may help with this. Some supervisors may agree to read chapters in their totality, and, eventually, even read and comment on a whole dissertation. Other supervisors, however, may only agree to read sections of work. Other important issues to agree on could include, for example, practical arrangements for the preparation of dissertation drafts and for feedback on 
these. Students - and sometimes supervisors - can underestimate the amount of time needed by lecturing staff to read and comment on students' work. It is, therefore, worth clarifying at the outset the length of time required between submitting a piece of work and meeting for feedback. Agreeing a mechanism for the feedback of comments is worth discussing, too. It may be, for example, that both student and supervisor agree to exchange work and comments via electronic mail, rather than always meeting face-to-face.

Various other practicalities, too, can be usefully clarified between student and supervisor at the start of the dissertation process. These include exchanging contact details, and making arrangements where necessary to provide support during periods when supervisors know they are going to be unavailable. Finally, as we discuss at further length below, it is worth, even at the earliest stage, beginning to map out a work plan and associated timetable. Most important of all, however, it is establishing a good working relationship between supervisor and student that is important; for dissertation supervision to be useful, supervisors and students need to be able to work effectively together.

\section{DEFINING A TOPIC}

The choice of topic for a dissertation will, to some extent, be determined by the nature of the degree for which it is being produced. A dissertation submitted for a BSc degree in Community Nursing, will, in all likelihood, need to be focused on an issue (or issues) of relevance to community nursing. Beyond such broad parameters, however, it is usually the case that students have considerable leeway in selecting an area in which to focus their studies. Indeed, part of the skill in producing a good dissertation is the ability to identify a specific area on which to concentrate, and to stick with this throughout. 
In our experience, not defining a clear topic for a dissertation and not keeping a sharp focus on this throughout are two very common errors that students seem to make. A test of the clarity of a topic for investigation might be the ability to express the nature of the investigation being undertaken in a single sentence. This is a useful device for helping to become focused on a very specific element of a particular topic.

Sometimes, the scope of proposed dissertations is too great. Wanting to find out everything that has been written about community mental health nursing, for example, is too far too grand - and imprecise - a topic for a dissertation. Wanting to explore the research-based evidence for a particular aspect of community mental health nursing practice, on the other hand, may be much more manageable and achievable.

Having settled on (and agreed with the supervisor) a manageable and suitably self-contained topic for the dissertation, it is equally important to stick to this topic from start to finish. It is important to avoid introducing literature into the dissertation which, whilst interesting, is also irrelevant.

\section{PLANNING THE WORK}

Armed with an interesting and well-defined topic area, a next useful step may be to begin mapping out a dissertation plan. This is, again, something to be done in consultation with the supervisor. Early tasks may include mapping out the precise aims and objectives of the piece of work, and working out an overall dissertation structure. It may also be worthwhile considering how the aims and objectives of the dissertation will be reflected in the sequencing and content of the individual dissertation chapters. 
Developing an idea of what the overall 'shape' of the completed dissertation will be like right at the outset is an activity well worth spending time on. Having done this, it is also worth thinking - in detail - about what tasks have to be done in order to complete the dissertation aims and objectives, and in order to produce the completed piece of work. Better still is the addition of timescales to these tasks. Planning when work is to be done may be particularly important for part-time students, and for those with multiple commitments to, for example, family members, colleagues and clients. Working backwards from the final submission date is one way of achieving this. If, for example, the dissertation needs to be handed in on June $30^{\text {th }}$, then it is important to establish by what date the completed work needs to be sent for binding and formal presentation. Other deadlines might include: the date by which a last dissertation draft may to be given to the supervisor to read, in order to allow final adjustments to be made before the completed work is sent for copying and binding; the date by which the final version of the literature review chapter needs to be written by; the date by which all relevant articles, books and reports to be included in the review need to be obtained; and the date by which a search of relevant databases will need to have been completed.

\section{THE LITERATURE REVIEW}

In any dissertation, getting hold of relevant literature and using this appropriately is a large (or even the largest) part of what is required. With the advent of internet-based or CD-ROM databases, such as CINAHL (Cumulative Index of Nursing and Allied Health Literature), searching for articles to use in pieces of work has become much easier. However, there is considerable skill in being able to search databases effectively. Just typing in a single word or series of words into CINAHL is likely to generate a thoroughly unmanageable mass of references. Learning how to combine searches, and how to limit searches according to 
particular criteria (such as to papers published only in UK journals) are strategies that are all well worth learning and using.

Even with well-defined search strategies, searching on-line databases and other sources of information is likely to lead to the amassing of a large volume of literature. This is also likely to come in a range of categories: reports of original research; conceptual and theoretical information; statistical information (such as data that is regularly gathered by central government); descriptive accounts (such as individual care studies); and personal opinion (Polit and Hungler 1999). In addition, the form in which different items of literature appears will vary. Information is likely to be found in: books; 'heavyweight' academic journals; 'professional' journals; conference abstracts; internet sites; national, local and professional policy documents; theses and dissertations; and so on (Parahoo 1997).

Although aimed predominantly at postgraduate readers, Hart's Doing a literature review (Hart 1998) gives some useful pointers to students searching for ways of organising and completing the literature review parts of their dissertations. Hart writes at length about the importance of being systematic. Useful tips include devising a standardised means of recording information from each item of literature. For example, a standardised record sheet stored either on a computer or on paper can carry bibliographic details - to enable the article or book to be retrieved when needed - along with information on the main theory, research evidence and argument put forward in each item. 'Maps' can also be useful, to plot the interrelationships between the research findings, theories and arguments which characterise the literature on the selected topic. 
A good literature review will be a demonstration of its author's ability to organise a large volume of information, appraise the relative merits of individual items of literature, and draw appropriate conclusions (Carnwell and Daly 2001). One of the first considerations when faced with a large quantity of literature on a chosen topic is to think about the overall 'character' of the literature. It is worth noting the balance in the available literature between the number of opinion pieces, the number of original research papers, and the quantity of theoretical items. Questions to be considered when dealing with the theoretical aspects of the literature on the chosen subject area might include: is there a consensus regarding the meaning or nature of the topic; are there counter-arguments; and what is the author's view of these arguments and counter-arguments (Carnwell and Daly 2001)? In relation to items of research, it is important to think about the quality of what has been produced. This, as Carnwell and Daly suggest, means considering the main strengths and weaknesses of individual studies.

It may also be useful to consider other aspects of the overall 'character' of the literature. Sometimes, literature on a the topic will naturally break down into sub-sections, which could, in turn, be used as a way of presenting the review in the completed dissertation. For example, a recent dissertation produced by a student whose work was being supervised by one of the authors, was concerned with the topic of "falls in older people with dementia". The student's search of the literature revealed that material dealing with the causes of falls in older people with dementia could, for the most part, be broken down into the following sub-sections: "psychological factors", "physiological factors" and "environmental factors". These subsections then became, in turn, a useful way of organising and presenting the literature which had been obtained and analysed. 
Having found a suitable way of organising the literature, the next crucial step is to actually write the review. There are a number of excellent books and journal articles which concentrate on the skill and process of writing in general, and on the particular skill of writing a literature review. A useful starting point for general guidance on writing is the online bibliography available at The Royal College of Nursing Research and Development Coordinating Centre's website (Hakesley-Brown and O'Carroll 2000). Here, a number of sources are cited, all of which are likely to provide valuable help to students wanting to sharpen their overall writing skills before starting work on the writing up of their literature reviews.

In addition to demonstrating good general academic writing skills, it is also important to demonstrate, in writing up the review, that 'the literature' has been subjected to critical analysis. Simply listing, in descriptive fashion, the articles and books that have been obtained and read through will not be enough. If a structured and critical approach has been taken to the searching, location and organisation of the literature, in the manner outlined above, then this task will be that much easier. It may be useful, at the start of the literature review section in the dissertation, to explicitly declare how literature has been obtained. It is increasingly common, for example, for students to spell out that they located the literature that they have reviewed through a search of a particular database/s, using a particular search strategy/strategies.

Similarly, it may be an equally helpful strategy to discuss, at the start of the review, the overall characteristics of the literature which has been consulted, in the way that we have discussed above. For example, if there is a dearth of original research in the chosen topic area, then this is well worth stating at the outset. 
It is important to avoid the 'bullet point' approach in presenting the detail of the literature review. Burnard (1996) writes of the importance of demonstrating skill in critical analysis. This means, for example, critiquing the methodology, sample size and findings of research papers. It also means comparing and contrasting studies, and drawing balanced conclusions. Similarly, in dealing with individual items of the literature, it is important to demonstrate the ability to critique the arguments and theories that writers have put forward. Related to this, it is important, too, that students writing dissertations are able to construct coherent and logical arguments of their own, and to base these on their reading and critiquing of the literature. Developing skills in literature reviewing, of the type we have drawn attention to here, takes both time and considerable practice. It is important, therefore, to make sure that plenty of space is allowed within the overall dissertation timetable to enable these literature-reviewing skills to be developed and refined.

\section{THEORY AND PRACTICE}

Nursing is a practice-based discipline. Either throughout the dissertation, or in a separate chapter towards the end, students will usually be required to show what the implications of 'the literature' are for the development of nursing care. Sometimes, the dissertation guidelines may ask for something very specific - and practice-based - in addition to the completion of a review of the literature. For example, it may be that the student has to construct a proposal for a service innovation, or a proposal for a small-scale, practice-based research project. Others may be required to complete a review of the literature on a chosen topic, and then use this to construct an educational innovation.

\section{KNITTING THE DISSERTATION TOGETHER}


One of the most important elements of a dissertation is the degree to which it is clearly and logically structured, and 'signposted'. Before starting work on the main body of the dissertation - the literature review - it is important, as we noted earlier, to have a clear idea of the overall 'shape' of the dissertation. Spelling out this 'shape' to the reader, and signposting key points along the way, is key to the construction of a good piece of work. For example, at the start of the dissertation it is worth setting out, clearly, what the aims and objectives are, and stating how the dissertation is structured in terms of chapters. At the start of individual chapters, it is worth spelling out what the focus of each chapter is, and what the individual chapter objectives are. Similarly, at the end of each chapter, it is important to pull together the material that has been presented, and to summarise key points. There are good examples of effective 'signposting' to be found in both published and unpublished work, and reading through these can be a useful learning exercise. Often, research reports, of the kind found in 'heavyweight' academic nursing journals or published as individual monographs, provide the best examples of how to structure and signpost work.

This 'signposting' can also usefully extend to the presentation of material within the body of each chapter. Using subheadings - just as the student who wrote a dissertation on "falls in older people with dementia" did - is a simple, but very helpful, device which will do much to guide the reader through the dissertation. Signposting in this way can act as a valuable 'advance organiser', and help to make sure that the reader (and the dissertation marker!) is not left wondering how the various parts of each chapter - and the dissertation as a whole are meant to 'fit together', 


\section{CONCLUSION}

We observed, at the start of this article, that more and more nurses are embarking on degreelevel study, and how for many of these people completion of a dissertation is a major part of what they are required to do. We have emphasised the importance of taking a structured approach to dissertations, both in terms of planning what has to be done and in actual dissertation 'writing up'. In doing this, we hope to have demystified and clarified what can seem, at the start, like a very daunting task. 


\section{REFERENCES}

Burnard P 1996 Writing for health professionals: a manual for writers. $2^{\text {nd }}$ edition. Stanley Thornes, Cheltenham.

Carnwell R, Daly W 2001 Strategies for the construction of a critical review of the literature. Nurse Education in Practice 1: 57-63. doi:10.1054/nepr.2001.0008

Hakesley-Brown R, O’Carroll D 2000 Writing for Publication Bibliography. Royal College of Nursing Research and Development Coordinating Centre.

http://www.man.ac.uk/rcn/writingbibliography.htm. [accessed May $5^{\text {th }}$ 2001]

Hart C 1998 Doing a literature review. Sage, London.

Parahoo K 1997 Nursing research: principles, process and issues. Macmillan, Basingstoke.

Polit DF, Hungler BP 1999 Nursing research: principles and methods. $6^{\text {th }}$ edition. Lippincott, Philadelphia.

The Quality Assurance Agency for Higher Education (QAA for HE) 2001 The framework for higher education qualifications in England, Wales and Northern Ireland. QAA for HE, Gloucester.

Snowball J, Ross K, Murphy K 1994 Illuminating dissertation supervision through reflection. Journal of Advanced Nursing 19: 1234-1240. 